Table II. Wound complications in operations employing straight dorsal wrist incision

\begin{tabular}{lccc}
\hline Author & $\begin{array}{l}\text { Number of } \\
\text { wrists }\end{array}$ & $\begin{array}{l}\text { Number of } \\
\text { complications }\end{array}$ & Per cent \\
\hline Swanson 1973 & 15 & 0 & 0 \\
Rana and Taylor 1973 & 77 & 0 & 0 \\
Mikkelson 1980 & 59 & 0 & 0 \\
Abernethy and Dennyson 1979 & 40 & 2 & 5 \\
Meuli 1980 & 41 & 2 & 5 \\
Mannerfelt and Malmstein 1971 & 43 & 4 & 10 \\
Noble 1987 & 93 & 6 & 6 \\
Total & 368 & 14 & 3 \\
\hline
\end{tabular}

When a "standard" incision was used our complication rate was higher, $21 \%$ ( 4 cases in 19 wrists); three patients had delayed healing and one had secondary haemorrhage requiring further surgery.

Discussion. The most striking feature in Table $I$ is the wide variation in quoted complication rates. Perhaps one man's delayed healing is not another's. What seems clear however is the lower incidence of wound complications when a straight incision is used. The extent of surgery performed had little bearing on wound problems; some minor surgery produced high complication rates (Rana and Taylor 1973), while more extensive procedures produced none (Carroll and Dick 1971).

All surgical incisions are designed primarily to give "adequate accurate access"; in no instance did a straight incision prove inadequate in this respect. Straight incisions are re-usable, a considerable advantage in the rheumatoid patient who may eventually need several wrist operations. Moreover, the scars produced by straight dorsal incisions never formed contractures and the cosmetic results were invariably good. For these reasons, and because they have no disadvantages we strongly recommend the use of straight incisions on the dorsum of the wrist.

\section{REFERENCES}

Abernethy PJ, Dennyson WG. Decompression of the extensor tendons at the wrist in rheumatoid arthritis. J Bone Joint Surg [Br] 1979;61-B:64-8.

Carroll RE, Dick HM. Arthrodesis of the wrist for rheumatoid arthritis. J Bone Joint Surg [Am] 1971:53-A :1365-9.

Lichtman DM, Mack GR, MacDonald R, Gunther SF, Wilson JN. Kienböck's disease: the role of silicone replacement arthroplasty. J Bone Joint Surg [Am] 1977;59-A :899-908.

Mannerfelt L, Malmstein M. Arthrodesis of the wrist in rheumatoid arthritis. Scand J Plast Reconstr Surg 1971:5:124-30.

Meuli HC. Arthroplasty of the wrist. Clin Orthop 1980:149:118-25.

Mikkelsen OA. Arthrodesis of the wrist in rheumatoid arthritis. Hand 1980;12:149-53.

Millender LH, Nalebuff EA. Arthrodesis of the rheumatoid wrist : an evaluation of sixty patients and a description of a different surgical technique. J Bone Joint Surg [Am] 1973:55-A :1026-34.

Millender LH, Nalebuff EA, Albin R, Ream JR, Gordon M. Dorsal tenosynovectomy and tendon transfer in the rheumatoid hand. $J$ Bone Joint Surg [Am] 1974;56-A :601-10.

Papaioannou T, Dickson RA. Arthrodesis of the wrist in rheumatoid arthritis. Hand 1982;14:12-6.

Rana NA, Taylor AR. Excision of the distal end of the ulna in rheumatoid arthritis. J Bone Joint Surg [Br] 1973:55-B:96-105.

Swanson AB. Flexible implant arthroplasty for arthritic disabilities of the radiocarpal joint: a silicon rubber intramedullary stemmed flexible hinge implant for the wrist joint. Orthop Clin North Am 1973;4:383-94.

\title{
SCIATIC PALSY FOLLOWING REDUCTION OF A DISLOCATED PROSTHESIS: BRIEF REPORT
}

\author{
I. STOCKLEY, D. BICKERSTAFF
}

Case report. A 74-year-old lady underwent a left exchange hip arthroplasty for aseptic loosening. Fourteen years previously, she had had a left Müller total hip replacement for osteoarthritis. At the second operation the hip was exposed using a trochanteric osteotomy and a complete capsulectomy was performed, the sciatic nerve being identified and protected throughout. Immediately

I. Stockley, FRCS, Sir Harry Platt Research Fellow

Department of Orthopaedics, Hope Hospital, Eccles Old Road, Salford, Lancashire M6 8HD, England.

D. Bickerstaff, FRCS, FRCS Ed, Orthopaedic Registrar

King Edward VII Orthopaedic Hospital, Rivelin Valley Road, Sheffield, S6 5SU, England.

Correspondence to $\mathrm{Mr}$ I. Stockley.

(C) 1988 British Editorial Society of Bone and Joint Surgery $0301-620 \mathrm{X} / 88 / 2 \mathrm{R} 48 \$ 2.00$

J Bone Joint Surg [Br] 1988;70-B:329-30. after the operation there was no evidence of a sciatic nerve palsy, but 18 hours later the patient complained of severe pain in the left hip after being turned. The radiograph showed a posterior dislocation of the femoral prosthesis.

A closed reduction was performed but, on recovering from the anaesthetic, the patient complained of pain down the back of the left leg from buttock to toes. She had patchy loss of sensation in the lower leg and a total sciatic motor palsy. The hip was therefore explored and the sciatic nerve was found to be stretched over the front of the neck of the prosthesis (Fig. 1). We were unable to release the nerve without dislocating the hip so the trochanter was detached again and the hip dislocated. Once released, the nerve lay without tension; the hip was relocated and the trochanter reattached. Immediately 
after this operation, the patient had active extension and flexion of the toes and within three weeks had no sensory deficit and Grade 4 motor power in the muscles of the foot and ankle.

Discussion. The reported incidence of neurological complications following total hip arthroplasty varies from $0.7 \%$ (Weber, Daube and Coventry 1976) to 3.7\% (Wilson and Scales 1973). Sciatic palsy is, however, said to occur in $13 \%$ of cases after posterior fracturedislocations of the hip (Epstein 1974). Our patient had a posterior dislocation of the femoral component, but this case is, we believe, unique as the sciatic nerve seems to have been "picked up" by the femoral prosthesis when the dislocated hip was reduced. This we deduce from the fact that there were no symptoms or signs prior to this event.

We immediately explored the hip as advocated by Fleming, Michelson and Stinchfield (1979). Our presumptive diagnosis of nerve compression by a haematoma was incorrect; nevertheless we agree that early reexploration of a complete postoperative sciatic palsy is advisable.

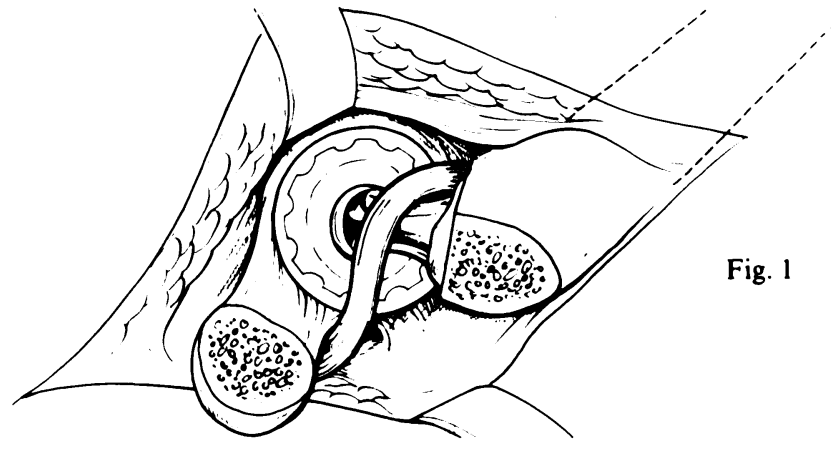

REFERENCES

Epstein HC. Posterior fracture-dislocations of the hip: long-term follow up. J Bone Joint Surg [Am] 1974;56-A:1103-27.

Fleming RE Jr, Michelson CB, Stinchfield FE. Sciatic paralysis: a complication of bleeding following hip surgery. J Bone Joint Surg [Am] 1979;61-A:37-9.

Weber ER, Daube JR, Coventry MB. Peripheral neuropathies associated with total hip arthroplasty. J Bone Joint Surg [Am] 1976;58-A :66-9.

Wilson JN, Scales JT. The Stanmore metal on metal total hip prosthesis using a three pin type cup: a follow-up of 100 arthroplasties over nine years. Clin Orthop 1973;95:239-49.

\section{INTERPROSTHETIC DISLOCATION OF THE CHARNLEY HASTINGS PROSTHESIS: BRIEF REPORT}

\section{P. J. RAE, R. W. PATON}

The Charnley Hastings prosthesis is a hybrid hemiarthroplasty consisting of a Hastings acetabular component, and a Charnley femoral component. This combination is sanctioned by the manufacturers. We report three cases of interprosthetic separation, a complication which, as far as we know, has not previously been reported with this prosthesis.

Case histories. All three patients were elderly ladies, aged respectively 75,92 and 84 years. In one the direct lateral approach was used, in another the lateral approach with trochanteric osteotomy, and in the third the posterior approach. In all three the recommended technique was used. At the conclusion of each operation the hip was stable and the postoperative radiographs were all satisfactory.

In two cases the hybrid prosthetic hip dislocated intact from the acetabulum, but an interprosthetic dislocation (that is, a separation between the two components) occurred on attempted closed reduction. The operative manipulations were performed by experienced surgeons without undue force. The third interprosthetic dislocation followed a fall. All three

P. J. Rae, FRCS, Orthopaedic Registrar

Park Hospital, Moorside Road, Manchester M31 3SL, England.

R. W. Paton, FRCS, Orthopaedic Registrar

Hope Hospital, Eccles Old Road, Salford M6 8HD, England.

Correspondence to $\mathrm{Mr} \mathbf{R}$. W. Paton.

(C) 1988 British Editorial Society of Bone and Joint Surgery

$0301-620 X / 88 / 2$ R $50 \$ 2.00$

J Bone Joint Surg [Br] 1988;70-B:330. required open reduction; the original components, which were undamaged, were retained and there were no redislocations.

Discussion. The Hastings head is a "snap" fit with no locking system. The head is very difficult to snap in and out of the socket when in the neutral position, but it is easy to lever the head out when the socket abuts against the neck of the femoral stem (Fig. 1). We suggest that this levering action is the mechanism of component separation. In two of our three cases the Hastings head had subsequently "button-holed" through the soft tissues and this prevented closed reduction.

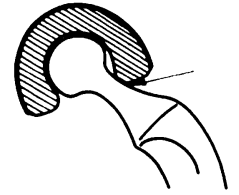

Fig. 1

Devas and Hinves (1983) reported two cases of interprosthetic dislocation with the Hastings hip. They stated that this was due to faulty prototypes, but we feel that the levering action described is a more likely cause, and that the lack of any locking device between the two components is a distinct disadvantage.

The authors would like to express their thanks to Mr D. R. A. Davies and Mr P. L. Frank for permission to report their cases. We also wish to thank Mr N. B. Lonsdale for the illustration.

REFERENCE

Devas M, Hinves B. Prevention of acetabular erosion after hemiarthroplasty for fractured neck of femur. J Bone Joint Surg [Br] $1983 ; 65-\mathrm{B}: 548-51$ 